\title{
Research on the Resilient Regeneration and Planning of Aging Community in the Post COVID-19 Era
}

\author{
Ning Chai* Xin Fan Jing Liu \\ School of Architecture and Art Design, Hunan University of Science and Technology \\ Xiangtan(411100), China \\ *Corresponding author Email: n.chai@qq.com
}

\begin{abstract}
COVID-19 has swept around the world, cities has suffered unprecedented challenges such as economic halt, limited interpersonal interaction and compressing space. The epidemic has suppressed the vitality of urban space, resulting in its weaken socioeconomic function. In particular, the elderly population over 65 years old is in a period of strong social demand, but their economic and social activities are reduced. We need to summarize and reflect on the vulnerability characteristics and health and safety problems of the cities under the impact of the epidemic, and strengthen the resilience of the city and ensure the urban health and safety are the focus of urban planning and governance in the future.This study explores the practical approaches of resilience regeneration and planning of aging community. By field investigation and statistical analysis of the case of Chengzheng aging community in Xiangtan City of China, it is found that the community environmental satisfaction of the elderly is significantly affected by outdoor activity time. This study propose some suggestions such as regenerating the internal space of the elderly community, increasing the cultural space, social community space and commercial space, so as to improve their accessibility of outdoor activities, and then improve the ability of aging communities to resist public health emergencies, promote the socio-economic activities of elderly and increase their health and happiness.
\end{abstract}

\section{Keywords}

Post COVID-19 era, aging community, resilience regeneration and planning 


\section{Theoretical evolution of resilience city}

\subsection{Concept and theoretical evolution}

The process of global urbanization is accelerating unprecedentedly, and the various risks and crises faced by cities are gradually increasing. Urban managers have to think about the planning methods and models of how to deal with those risks and crisis, namely to strengthen the resilience of the city. (Coaffee \& Lee, 2016) Urban and regional planning plays a key role in defining urban resilience, coping with the crisis, and strengthening urban resilience.

The term "urban resilience" first appeared in ecological field in 1970s (Coaffee \& Wood,2006). Holling (1973) put forward the concept of "ecosystem resilience" — the persistence that natural system respond to ecosystem changes caused by natural or man-made reasons.Two decades later, Holling (2002) first applied the "ecosystem resilience" to human society and an "adaptive cycle" model is proposed to describe the interaction between disturbance and reorganization and its resilience change in social-ecosystem. From 2001 to 2007, American urban and regional planners, ecologists and environmentalists began to study the response of urban systems to disaster risks.(Holling,1996; Pickett,2004; Clout et al.,2007) Since then, the concept of "resilience" has been applied by many disciplines, and the research object has expanded from "ecosystem resilience" to "social ecosystem resilience". Hereafter, "resilience" has become an effective way to understand the urban social and ecological structure.(Folke,2006) Since 2008, with the improvement of response awareness to financial crisis, global warming, extreme disasters, urban terrorist attacks and other crises, researchers in different fields around the world have joined the research of resilient cities.(Evans,2011; Desouza \& Flanery, 2013; Pendall et al, 2010)

From 2001 to 2007, the concept of "resilience" has been widely used in the study of urban system's adaptability to unpredictable, large and uncertain disasters in the future. (Hatuka,2018; Bigger \& Webber,2021) Since 2008, researchers from the fields of engineering, public management, computer science, sociology, economics and other disciplines all over the world have joined the research team of resilient cities, which contributed to the interdisciplinary development.(Wildavsky,1988) Thus, the concept of resilience has been widely used in the research of adaptive strategies of urban system in the face of unpredictable, large and uncertain environmental change in the future, which has become the focus of current research. (Barnett,2001; Thomalla et al., 2006) 
Table 1. Change of Perspective of Resilience Theory

\begin{tabular}{|c|c|c|c|}
\hline $\begin{array}{l}\text { Perspective from } \\
\text { resilience }\end{array}$ & $\begin{array}{l}\text { Resilience of } \\
\text { Engineering }\end{array}$ & $\begin{array}{l}\text { Resilience of ecological } \\
\text { system }\end{array}$ & $\begin{array}{l}\text { Social ecological } \\
\text { resilience }\end{array}$ \\
\hline Characteristic & $\begin{array}{l}\text { Resilient time } \\
\text { and efficiency }\end{array}$ & $\begin{array}{l}\text { Buffering capacity Impact } \\
\text { resistance Function } \\
\text { maintenance }\end{array}$ & $\begin{array}{l}\text { Reorganization } \\
\text { Maintenance } \\
\text { Development }\end{array}$ \\
\hline Focus & $\begin{array}{l}\text { Recovery constant } \\
\text { and persistence }\end{array}$ & Immunity and adaptability & $\begin{array}{l}\text { changeability, learning and } \\
\text { innovation }\end{array}$ \\
\hline Context & $\begin{array}{l}\text { Adjacent to a single } \\
\text { equilibrium state }\end{array}$ & Multiple balances & $\begin{array}{l}\text { Adaptive cycle, integrated } \\
\text { system feedback, and } \\
\text { cross-scale dynamic } \\
\text { interaction }\end{array}$ \\
\hline
\end{tabular}

Source:C. Folke(2006), Liao K.H.(2012) and Gunderson L. H.(2001)

\subsection{Research progress of resilient city}

Compared with the traditional concept of disaster reduction, urban resilience pays more attention to the social dimension of the city and the non-material conditions of the city in response to disasters. The concept of resilience is of great significance to urban planning. On one hand, it provides a new way to respond to uncertainties in spatial planning and urban development, and on the other hand, it provides a paradigm for urban development strategies to cope with large-scale social, environmental or economic changes. By using the concept of resilience, urban planning can be linked to natural and ecological systems and social and human elements on the other, both of which are the focus of planning efforts. From the end of 1990s, some researches on the relations between resilience and urban planning absorbed academical attention, and emphasized "preparation and mitigation action". (Godschalk,2003)

Later, the literature on resilient planning was broadened to mitigation strategies, such as reducing greenhouse gas emissions and coping with climate change. In recent years, the challenge of climate change has become more obvious, and planners and policymakers are gradually aware of using the mitigation approach to ensure complete security is very difficult (or impossible), while the resilience strategy is more adaptive and flexible.(Fleischhauer $M, 2008$ )

Researchers proposed a framework of resilient urban planning called "vulnerability analysis, urban governance, prevention and uncertainty-oriented planning", which incorporates mitigation and adaptation. Actually, there are many studies on resilient cities emphasizing different facets 
of urban resilience. The theoretical challenge is to put multiple urban dimensions (social, economic, cultural, environmental) into a unified framework, and proposed a resilient city framework composed of vulnerability analysis, urban governance, prevention and uncertaintyoriented planning framework (see Fig.1). (Jabareen,2013) Firstly, the vulnerability analysis is used to identify the relatively vulnerable groups and communities in the city, to assess the scale of urban informal space and social, economic and environmental conditions, and meanwhile analyze uncertainties in the future of the city, as well as to express the above information by spatial distribution.(Satterthwaite,2013) Secondly, government control mechanisms should be established to incorporate diverse participants related to resilience into the planning collaboration process and formulate effective actions to mitigate climate change.(Burton,2015) Thirdly, preventive strategies should be implemented to reduce greenhouse gas emissions in cities and promote alternative energy sources. Finally, uncertain-oriented planning, should be formulated to regulate disaster-prone areas through land use management, block and building design, in order to create a sustainable urban form.(Jabareen,2013)

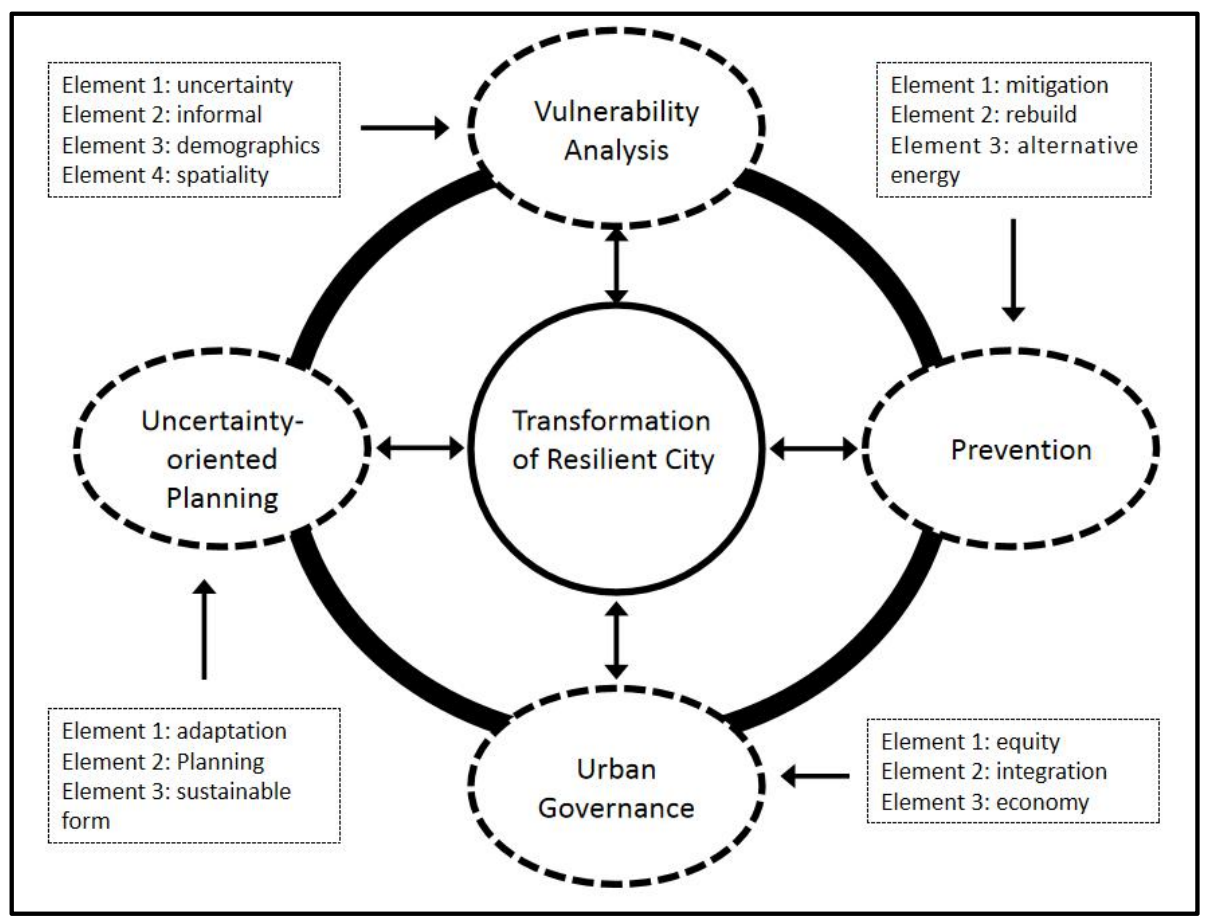

Figure 1. Framework of resilient urban planning

Source: Jabareen Y. (2013) (Adjusted by authors) 


\section{Threats to aging urban communities affected by COVID-19}

\subsection{Impact of epidemic on aging communities}

With the aggravation of population aging, such as Japan, Hong Kong, Singapore, Taiwan, South Korea, etc.(Fig.2), aging communities have emerged in many cities, namely, most residents there are the elderly over 65 years old. Since the end of 2019, COVID-19 has been raging around the world, and the health of the elderly has been unprecedentedly threatened. Compared with climatic natural disasters, epidemics test the resilience of cities more strictly. Many scholars began to study the impact of new crown epidemics on aging communities, and found that under the influence of the COVID-19, the physical health of the elderly has been threatened, moreover, some community spaces have been closed due to the need of epidemic prevention.(Portegijs et al.,2021) Aging communities often have high population density, narrow roads and poor mobility, and the low level of infrastructure construction is not allowed to maintain the physical distance of outdoor space. The scope of activities of the elderly population is limited, unlike the young people who can often go out to the open public space in the area for social networking, and during the epidemic, thus, most elderly have to stay at home inevitably, and their social activities have been seriously affected, resulting in worse mental health.(Parikh et al., 2020) Some comparative researches proposed that after the occurrence of COVID-19, the number of destinations for elderly decreased significantly with spatial activities limited, and their quality of life were decreased concomitantly. (Suzuki et al., 2020) Epidemic prevention policies made by governments around world have affected the activity space of the elderly, and some researches explore whether the regeneration of aging communities would eliminate the negative impact from COVID-19 on the elderly's activity space and improve their quality of life. (Levinger et al., 2021)

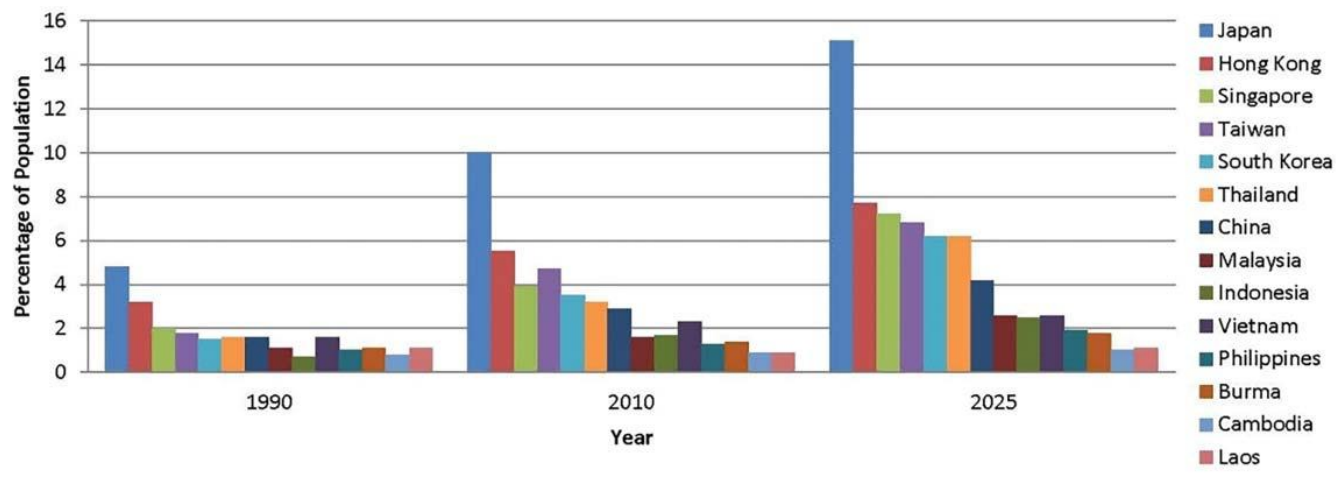

Figure 2. Age profiles of selected Asian economics

Source: Loo, et al.(2017) 


\subsection{Resilient regeneration of aging communities}

Affected by COVID-19, the main academic focus of urban aging community is the social communication activities of the elderly, which is the necessary guarantee for them to improve their mental and physical health, and has been widely recognized academically. Generally, COVID-19 is likely to coexist with human beings for a long time, in order to protect the physical and mental health of the aging population and promote the sustainable development of the aging community, it is necessary to think about the resilient regeneration and planning of the aging community in the post COVID-19 era. Integrating epidemic prevention and control into urban spatial planning is conducive to improving the level of urban infrastructure and housing, especially for the regeneration of aging communities. The research on resilience regeneration of aging communities is mostly carried out from the aspects of spatial satisfaction(Yung et al., 2019), local attachment and perception to the environment (Sun et al.,2020), social network activity(Choi et al.,2018), community environment (Leung \& Liang,2019), open space building(Subramanian \& Jana,2018), etc. It is found that in the post COVID-19 era, while meeting the needs of the elderly for epidemic prevention, we should strengthen the creation of the public open space for the elderly community, so as to meet elderly's needs for community activities, enhance their attachment and perception to the local community, improve the frequency of social interaction, promote their physical and mental health, minimize their normal life influenced by COVID-19, as well as improve the spatial resilience of aging communities. (Bhuyan \& Yuen,2021; Zhang \& Chan,2020; Yung et al, 2016; Loo et al., 2017)

\section{Current situation of Chinese aging community in post COVID-19 age}

\subsection{Introduction to the case of Chinese aging community}

This study selects the Chengzheng old community of Xiangtan City in China as the objective site (Fig.3). This area is the birthplace of Xiangtan City, with a history of nearly 1000 years. Nowadays, however, it has become the oldest urban area in the city and the proportion of the elderly population over 65 years old exceeds $80 \%$, which can be seen as the aging community. 


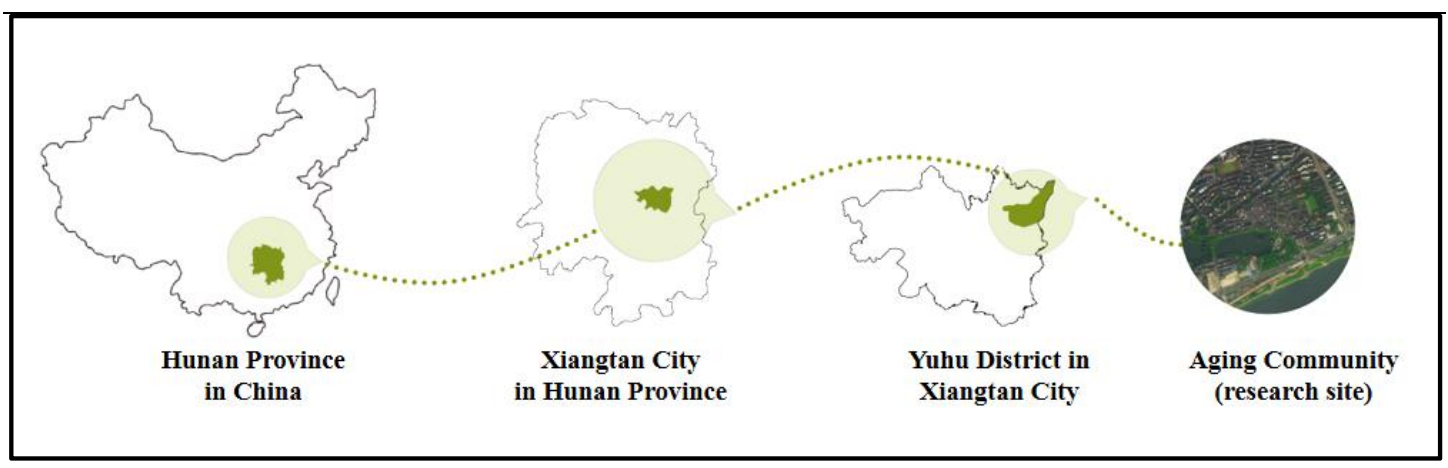

Figure 3. Location of aging community (research site)

(Drawn by authors)

As shown in Fig.4, the selected aging community in this study is located in the northwest of the old community in Chengzheng street. More than $80 \%$ of the residents in the aging community are over 65 years old, and the proportion of elderly residents in communities outside the region is relatively small. The old community of Chengzheng street is mainly residential buildings, with few public and commercial buildings. Due to its long history and culture, there are a small number of historic buildings(Fig.5). In terms of the building quality of old communities, about $35 \%$ of the buildings on the site are of poor quality, mainly residential buildings, and most of the buildings with good quality are commercial and public (Fig.6). In terms of building floors, buildings with more than 7 floors are mostly public buildings, and that of 4-6 floors are mainly commercial ones, while residential buildings are mostly old-fashioned traditional residential buildings with 1-3 floors.(Fig.7) 


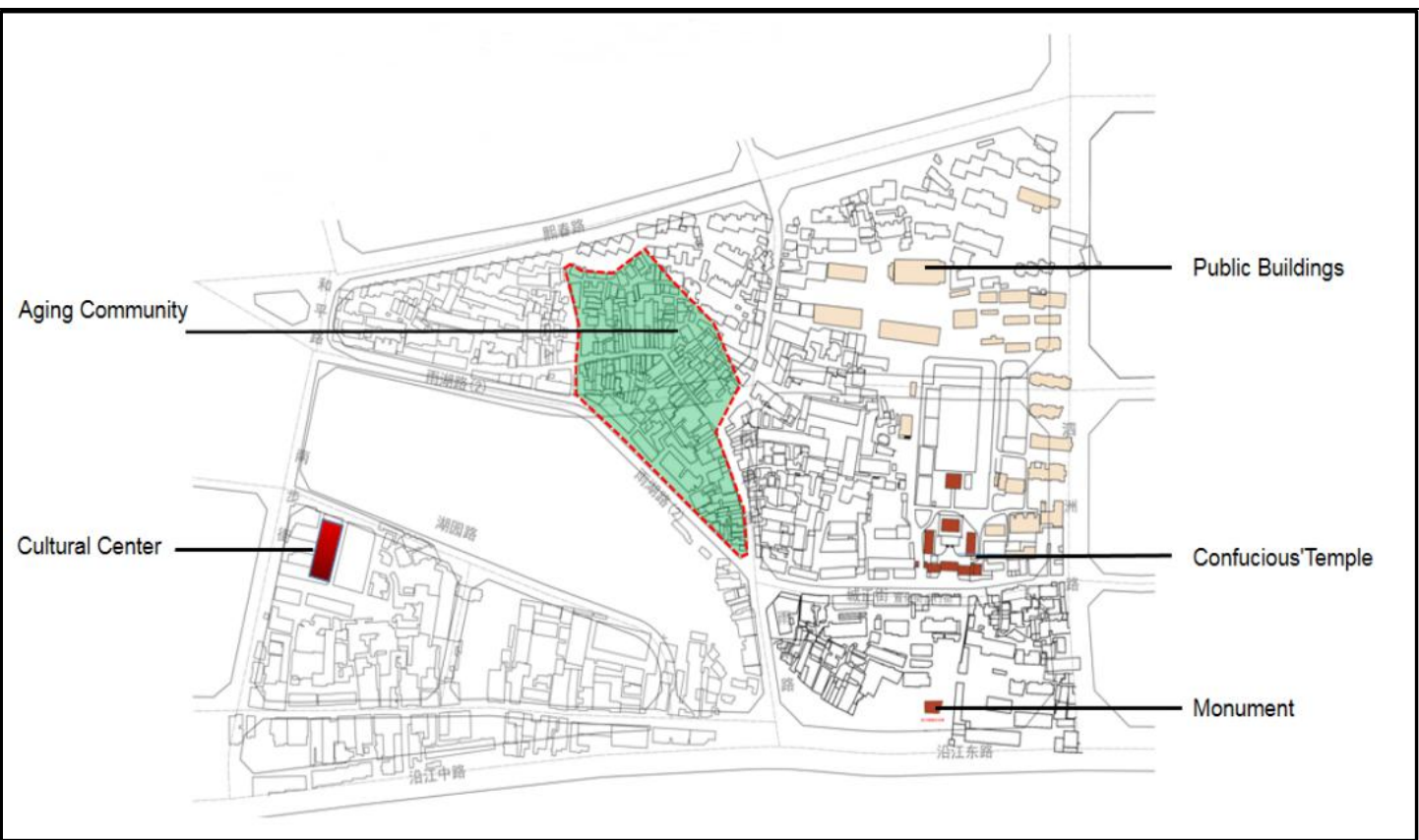

Figure 4. Planar graph of Chengzheng old community

(Drawn by authors)

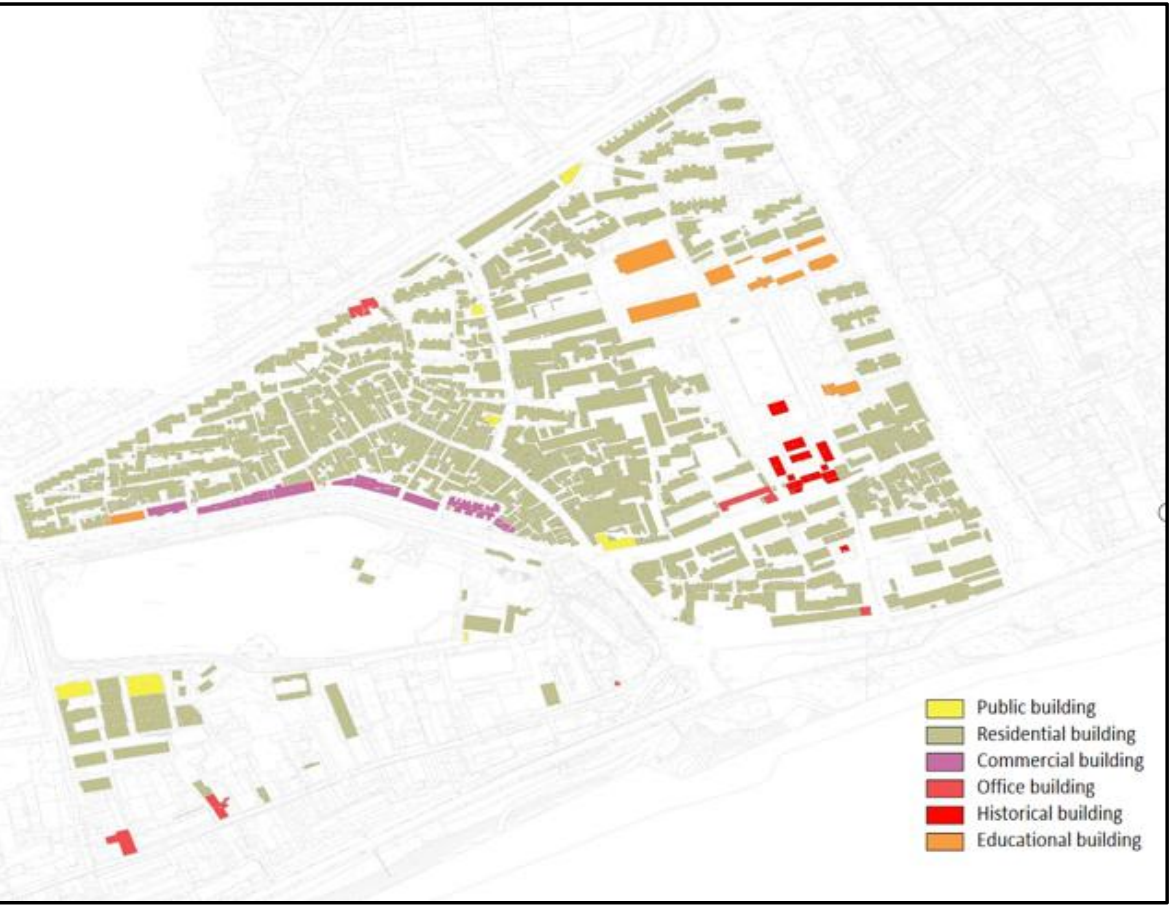

Figure 5. Distribution of functional buildings

(Drawn by authors) 


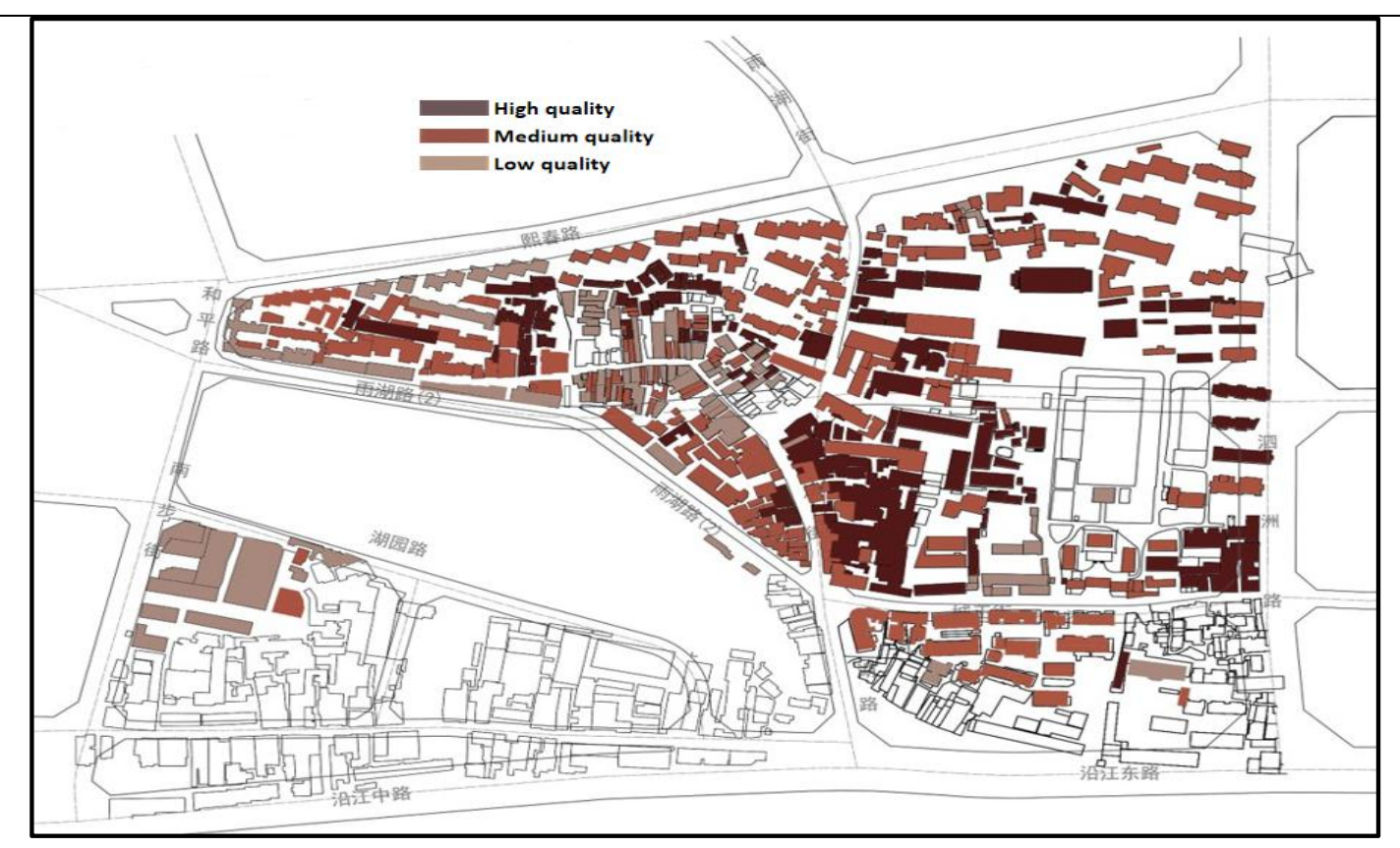

Figure 6. Distribution of quality of buildings

(Drawn by authors)

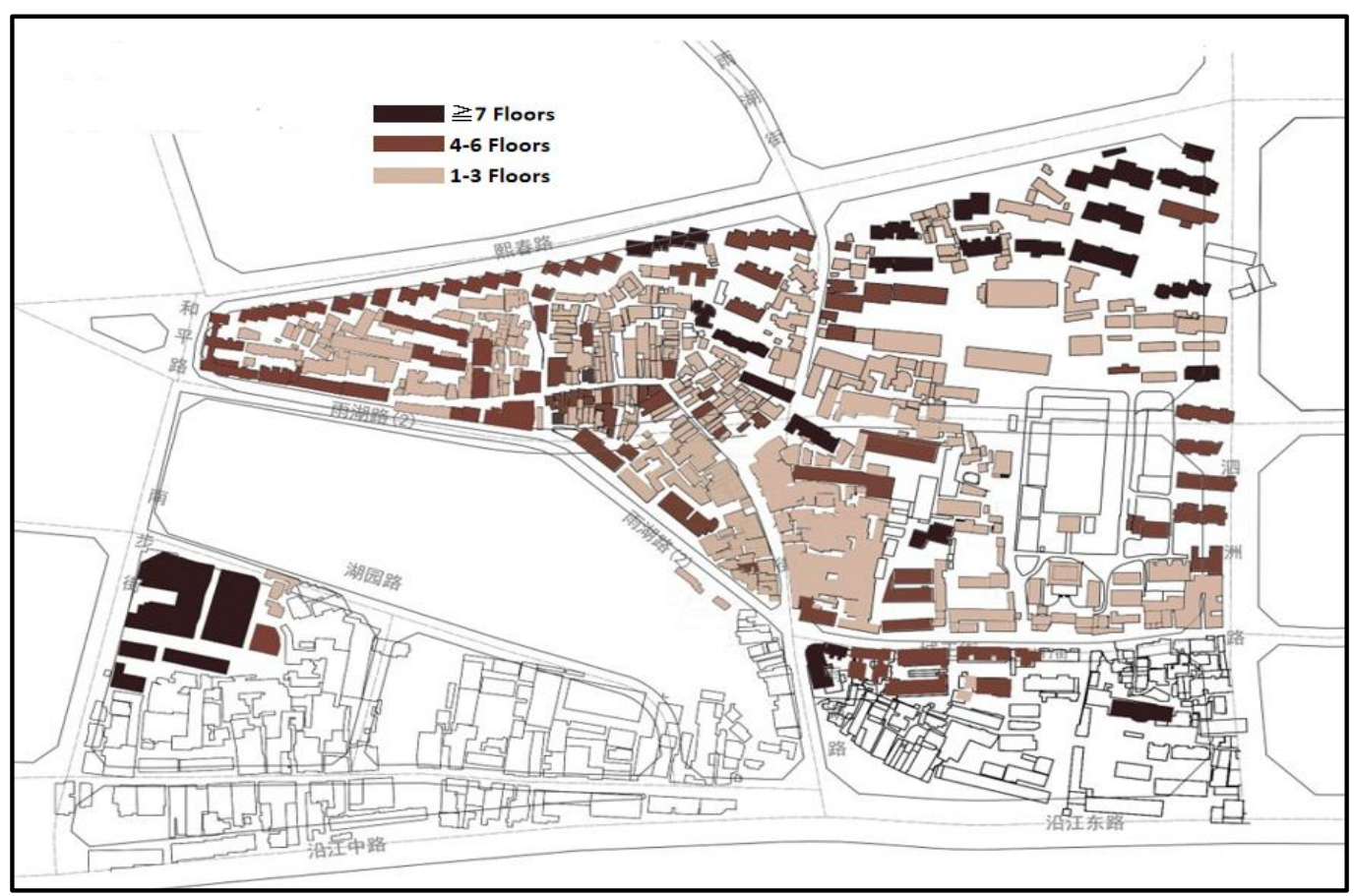

Figure 7. Distribution of floors of buildings

(Drawn by authors) 


\subsection{Current situation and problems faced by aging communities}

\subsubsection{The travel of the elderly population has been seriously affected}

Influenced by COVID-19, travel activities of elderly people over 65 years old in Chengzheng aging community have been seriously affected. From the big data of regional travel heat map from 2019 to 2021, the travel heat of aging communities shows a decreasing trend year by year (Fig.8), which poses a serious threat to the physical and mental health of the elderly living there. After the outbreak of COVID-19, the research group collects 238 data samples of people over 65 years old through the visits and questionnaires (from 2020.10 to 2021.05 ), and finds out that after the epidemic prevention measures are carried out, although the epidemic has brought depression to most of the elderly, the proportion of elderly people who are persisting in travel has the lowest tendency to get depression.(Fig.9)

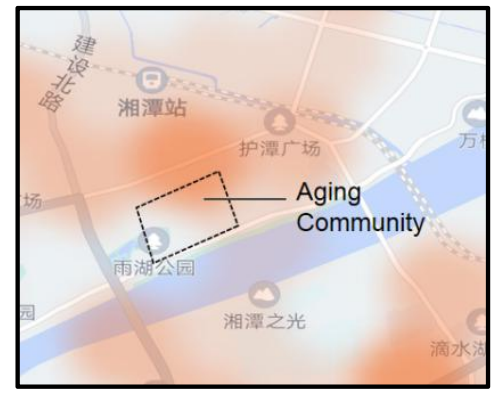

2019

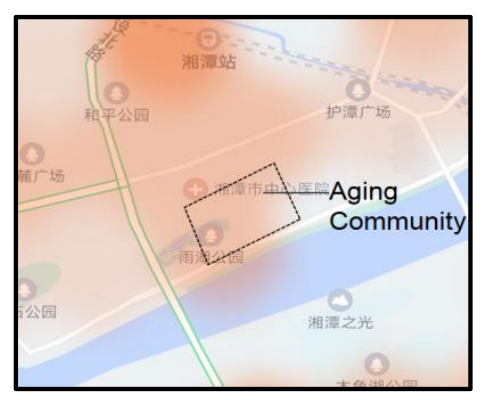

2020

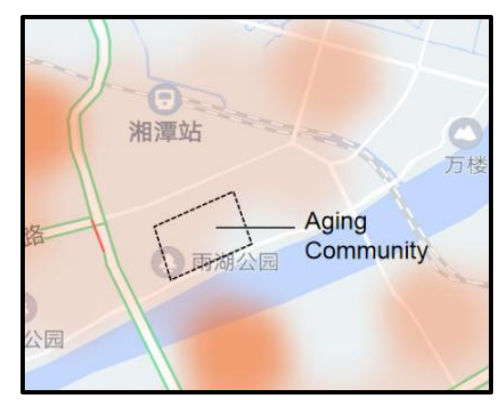

2021

Figure.8 Annual average change of travel frequency in aging communities (2019-2021)

Source: Drawn based on Gaode travel big data 


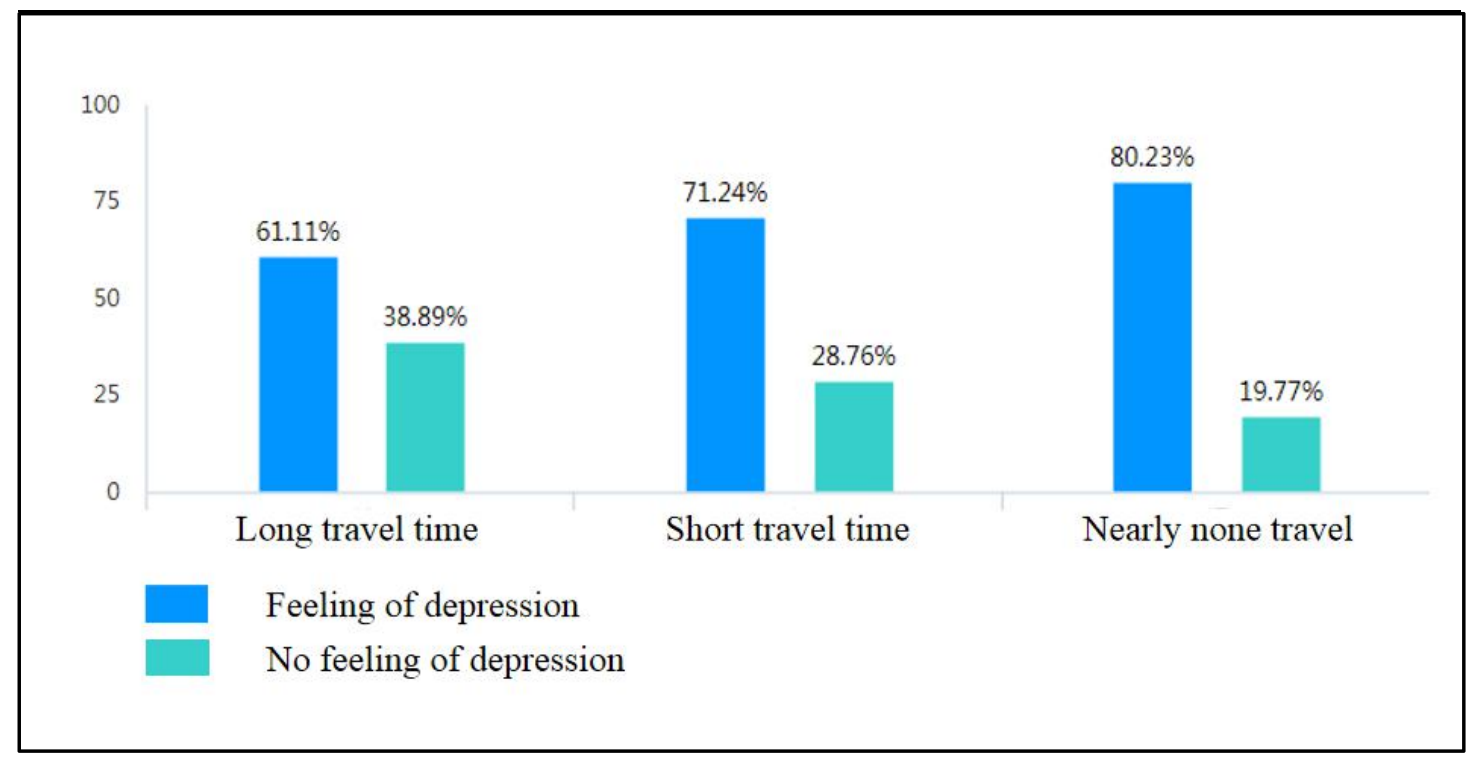

Figure.9 Relationship between monthly travel time and depression in the group of elderly

Source: Questionnaire data analysis

\subsubsection{Relative poor living space quality for elderly in aging community}

Through field research, it is found that the living environment of the elderly in Chengzheng aging community is relatively poor, such as dilapidated buildings, outdated infrastructure, poor convenience of road system, lack of public space in the community, and worse health situation . Specifically, the traditional street space texture is messy, the living space is mixed with people and vehicles, the rest and commuting space are limited, the street scale is small, there are many roads with lower accessibility, and the neighborhood privacy is poor. In this case, once the epidemic breaks out, even if every resident stays at home, only an infected person will cause community transmission, which is also a disadvantage of the old community, just like the epidemic outbreak caused by community transmission in Mumbai slums. Therefore, in the post COVID-19 era, the aging community needs not only a closed system for epidemic prevention and safety, but also a public space to meet the social needs of the elderly, which is also the focus of the regeneration and planning for aging community. 

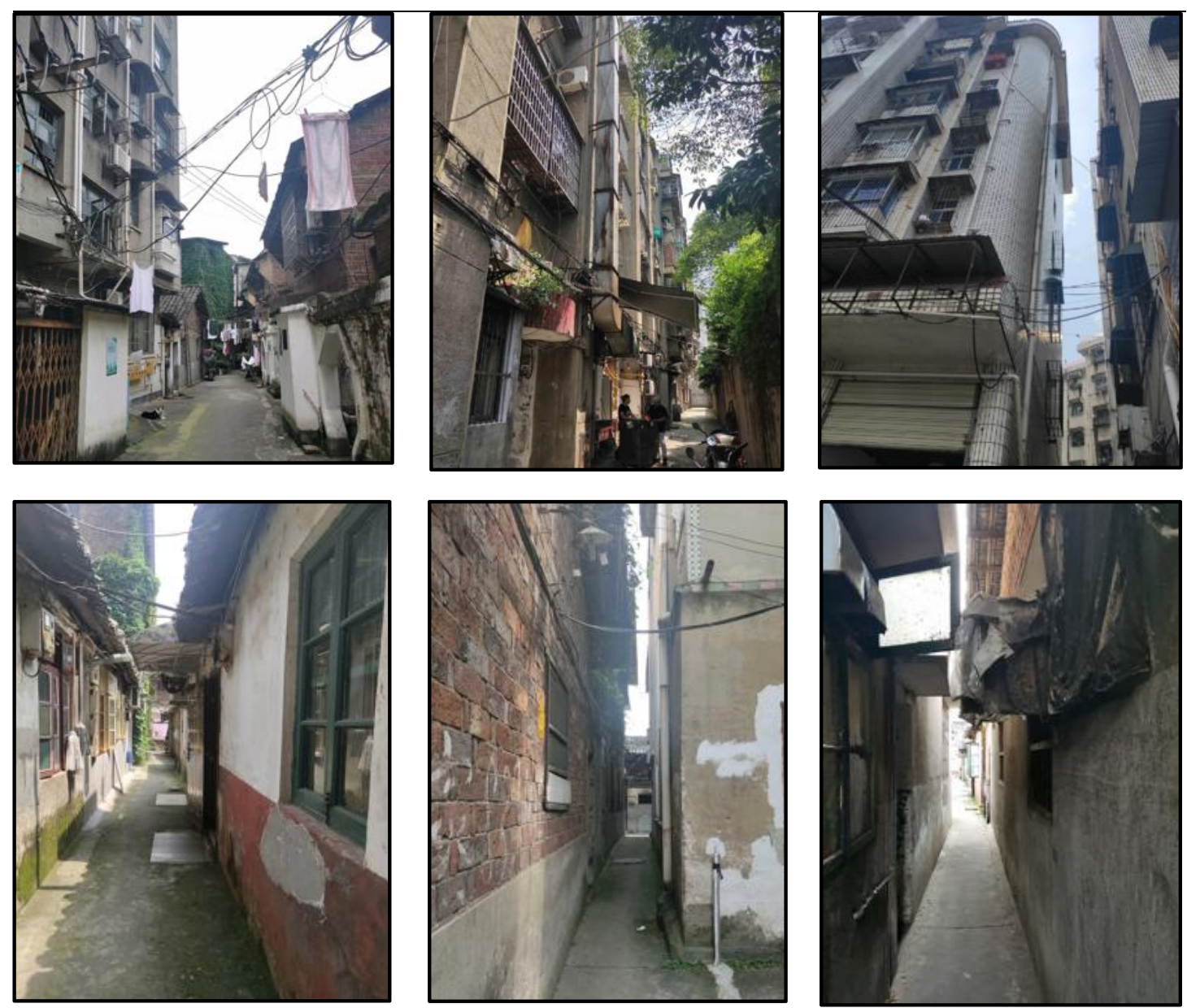

Figure 10. Poor living space quality in Chengzheng aging community

(all photos are taken by our research group)

\subsection{Influencing factors of elder's satisfaction for community environment}

This study conducted interviews and questionnaires with 423 residents of aging community to analyze their perception of the community environment and the influencing factors of this perception after the outbreak of the epidemic. "satisfaction of community environment" is selected as the affected factor (y), and the factors such as gender, age and education, economic factors, emotional factors and habit factors are selected as the influencing factors $(\mathrm{x})$ to construct a Multiple Logistic Regression Model. The analysis results by SPSS are as follows. The factors that have a statistically significant impact on the community environmental satisfaction of the elderly population include: gender, health, family's annual expenditure, living satisfaction, exercising time, preparing for pension, security and financial support for family.

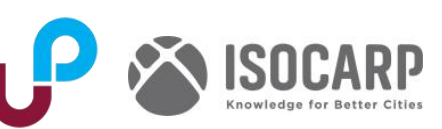


(1) Compared with "very dissatisfied with the living environment", on the premise of very satisfied, the regression coefficient of "gender" is 2.129 and presents a statistical significance of 0.01 level $(z=2.810, P=0.005<0.01)$, which means that "gender" has a significant positive impact on the satisfaction of community living environment, because the value of OR (odds ratio) is 8.405 , showing that compared with men, women's satisfaction with living environment is 8.405 times higher than men's. It can be seen that after the outbreak of the epidemic, female residents in aging community have stronger psychological adaptability to the environment than men.

(2) Compared with "very dissatisfied with the living environment", on the premise of feeling satisfied with the living environment, the regression coefficient of "health perception" is 0.599 , showing a statistical significance of 0.05 level $(z=2.015, P=0.044<0.05)$, which means that there is a significant positive correlation between health status and living environment satisfaction. As the $O R$ value is 1.820 , so when the health status of the elderly is good, the increase range from very dissatisfied to satisfied with the living environment is 1.820 . It can be seen that even under the condition of poor environmental quality of objective material space, good physical condition will increase the satisfaction of the elderly with the living environment.

(3) Compared with "very dissatisfied with the living environment", on the premise of feeling satisfied with the living environment, the regression coefficient of the elder's family expenditure is -0.723 and presents a statistical significance of 0.05 level $(z=-2.203, P=0.028<0.05)$, which means that the annual family expenditure has a significant negative correlation with the elder's living environment satisfaction. Because the $O R$ value of 0.458 shows that for every unit of annual household expenditure, the range of the elderly from satisfaction to very dissatisfaction with the living environment will increase by 0.485 times. It can be seen that because the research community is an aging community with relatively low economic income, they care more about how much money they spend than they can earn. Once the annual household expenditure exceeds a certain range, their satisfaction with the living environment will be reduced.

(4) Compared with very dissatisfied with the living environment, on the premise of feeling general about the living environment, the regression coefficient value of residents' "life satisfaction" is -1.557 , and shows a statistical significance of 0.05 level $(z=-1.991, P=0.047<0.05)$, which means that "life satisfaction" has a significant negative impact on "living environment satisfaction". Because the OR value is 0.211 , the change range of residents' satisfaction with the living environment from "very dissatisfied" to "feel average" will be reduced by 0.211 times for each unit of life satisfaction. Most elderly residents do not regard life and residence as a whole, which can also reflect that elderly residents can't stand the current living environment when they

\section{U i ISOCARP}


are satisfied in other aspects. Moreover, the more satisfied they are in other aspects, the higher their requirements for the living environment.

(5) Compared with very dissatisfied with the living environment, on the premise of very satisfied with the living environment, the regression coefficient value of the independent variable "average time of each exercise in recent year" is 1.404, and shows a statistical significance of 0.05 level $(z=2.436, P=0.015<0.05)$, indicating that "time of each exercise" will have a significant positive correlation with the satisfaction of the living environment of the elderly. As the OR value is 4.073 , and when each exercise time is increased by one unit, the change range from very dissatisfied to very satisfied with the living environment is 4.073 times. It is found that even affected by the epidemic, as long as residents can go out for physical exercise, they will greatly improve their satisfaction and happiness with the living environment.

(6) Compared with being very dissatisfied with the living environment, on the premise of feeling general about the living environment, the regression coefficient value of the independent variable "whether residents have saved or prepared for the elderly" is -0.920 , and shows a statistical significance at the level of $0.05(z=-2.379, P=0.017<0.05)$, indicating that there is a negative correlation between "saved or prepared for the elderly" and "satisfaction with living environment". Because the OR value is 0.399 , compared with no provision for pension savings, the reduction of the elderly with provision for pension savings from general to very dissatisfied with the living environment is 0.399 times. Thus, the more fully the elderly prepare for their own pension, the higher the requirements for the quality of the surrounding environment, because they have the ability to make economic investment to change this environment.

(7) Compared with being very dissatisfied with the living environment, on the premise of being very satisfied with the living environment, the regression coefficient value of the independent variable "sense of outdoor security" is 2.519 and presents a statistical significance at the level of 0.01 ( $z=4.454, P=0.000<0.01$ ), which means that "sense of outdoor security" has a significant positive impact on "satisfaction with the living environment". Because the OR value is 12.417 , the change range from very dissatisfied to very satisfied with the living environment is 12.417 times when the elder's sense of security increases by one unit. Obviously, the sense of security brought by the outdoor environment to the elderly directly affects the their satisfaction with the quality of living environment.

(8) Compared with very dissatisfied with the living environment, on the premise of feeling general about the living environment, the regression coefficient of the independent variable "financial support for family" is 0.729 , and shows a significant level of 0.05 ( $z=2.023, P=0.043<$ $0.05)$, which means that "financial support for family" will affect "satisfaction with the living 
environment" positively. Because the OR value is 2.073 , compared with the elderly who have no financial ability to support their families, the satisfaction of the elderly with this ability to the living environment will increase by 2.073 times. it can be seen that the harmony of family economic relations will improve the satisfaction of the elderly with living environment. 
Research on the Resilient Regeneration

and Planning of Aging Community

in the Post COVID-19 Era

Table 2. Results of Multiple Logistic Regression Analysis

\begin{tabular}{|c|c|c|c|c|}
\hline Influence factors & Dissatisfied & Commonly & Satisfied & $\begin{array}{c}\text { Very } \\
\text { satisfied }\end{array}$ \\
\hline Gender & $\begin{array}{l}1.402^{*} \\
(2.204) \\
\end{array}$ & $\begin{array}{c}1.661^{* *} \\
(2.711) \\
\end{array}$ & $\begin{array}{c}1.163 \\
(1.923) \\
\end{array}$ & $\begin{array}{r}2.129 * * \\
(2.810) \\
\end{array}$ \\
\hline Age & $\begin{array}{c}0.060 \\
(0.184) \\
\end{array}$ & $\begin{array}{c}0.002 \\
(0.005) \\
\end{array}$ & $\begin{array}{c}0.263 \\
(0.870) \\
\end{array}$ & $\begin{array}{c}0.206 \\
(0.541) \\
\end{array}$ \\
\hline Educational level (1=uneducated; ) & $\begin{array}{c}-0.078 \\
(-0.285) \\
\end{array}$ & $\begin{array}{c}0.148 \\
(0.555) \\
\end{array}$ & $\begin{array}{c}0.061 \\
(0.236) \\
\end{array}$ & $\begin{array}{c}0.420 \\
(1.233) \\
\end{array}$ \\
\hline Living condition & $\begin{array}{c}-0.109 \\
(-0.517)\end{array}$ & $\begin{array}{c}0.146 \\
(0.743) \\
\end{array}$ & $\begin{array}{c}0.036 \\
(0.188)\end{array}$ & $\begin{array}{c}-0.048 \\
(-0.207)\end{array}$ \\
\hline Health & $\begin{array}{c}0.417 \\
(1.324)\end{array}$ & $\begin{array}{c}-0.031 \\
(-0.101) \\
\end{array}$ & $\begin{array}{l}0.599^{*} \\
(2.015)\end{array}$ & $\begin{array}{c}0.205 \\
(0.528) \\
\end{array}$ \\
\hline What is your family's annual income? & $\begin{array}{c}-0.093 \\
(-0.284)\end{array}$ & $\begin{array}{c}-0.267 \\
(-0.860)\end{array}$ & $\begin{array}{c}0.003 \\
(0.010) \\
\end{array}$ & $\begin{array}{c}-0.697 \\
(-1.769)\end{array}$ \\
\hline What is your family's annual expenditure? & $\begin{array}{c}-0.575 \\
(-1.660)\end{array}$ & $\begin{array}{c}-0.607 \\
(-1.852)\end{array}$ & $\begin{array}{l}-0.723^{*} \\
(-2.203)\end{array}$ & $\begin{array}{c}-0.322 \\
(-0.759)\end{array}$ \\
\hline Satisfied with life & $\begin{array}{c}-1.116 \\
(-1.362)\end{array}$ & $\begin{array}{l}-1.557^{*} \\
(-1.991)\end{array}$ & $\begin{array}{c}-0.645 \\
(-0.817)\end{array}$ & $\begin{array}{c}-1.544 \\
(-1.524)\end{array}$ \\
\hline Have you given up many previous activities and hobbies? & $\begin{array}{c}0.067 \\
(0.100) \\
\end{array}$ & $\begin{array}{c}-0.342 \\
(-0.543)\end{array}$ & $\begin{array}{c}-0.468 \\
(-0.755)\end{array}$ & $\begin{array}{c}-0.302 \\
(-0.383)\end{array}$ \\
\hline Do you feel that your life is not full enough? & $\begin{array}{c}0.172 \\
(0.239)\end{array}$ & $\begin{array}{c}0.296 \\
(0.433) \\
\end{array}$ & $\begin{array}{c}-0.161 \\
(-0.239)\end{array}$ & $\begin{array}{c}0.743 \\
(0.843) \\
\end{array}$ \\
\hline Are you often upset? & $\begin{array}{c}0.185 \\
(0.249)\end{array}$ & $\begin{array}{c}-0.200 \\
(-0.283)\end{array}$ & $\begin{array}{c}0.130 \\
(0.185)\end{array}$ & $\begin{array}{c}0.181 \\
(0.210)\end{array}$ \\
\hline Do you feel refreshed most of the time? & $\begin{array}{c}-0.292 \\
(-0.370)\end{array}$ & $\begin{array}{c}0.250 \\
(0.334) \\
\end{array}$ & $\begin{array}{c}0.534 \\
(0.714)\end{array}$ & $\begin{array}{c}1.307 \\
(1.239)\end{array}$ \\
\hline Are you worried that something bad will happen to you? & $\begin{array}{c}-0.935 \\
(-1.343)\end{array}$ & $\begin{array}{c}-0.307 \\
(-0.469) \\
\end{array}$ & $\begin{array}{c}0.387 \\
(0.596) \\
\end{array}$ & $\begin{array}{c}-1.123 \\
(-1.317)\end{array}$ \\
\hline
\end{tabular}


Research on the Resilient Regeneration

and Planning of Aging Community

in the Post COVID-19 Era

\begin{tabular}{|c|c|c|c|c|}
\hline Influence factors & Dissatisfied & Commonly & Satisfied & $\begin{array}{c}\text { Very } \\
\text { satisfied }\end{array}$ \\
\hline Do you feel happy most of the time? & $\begin{array}{c}1.348 \\
(1.796) \\
\end{array}$ & $\begin{array}{c}1.218 \\
(1.717) \\
\end{array}$ & $\begin{array}{c}0.809 \\
(1.167) \\
\end{array}$ & $\begin{array}{c}1.448 \\
(1.447) \\
\end{array}$ \\
\hline Do you often feel helpless? & $\begin{array}{c}0.599 \\
(0.799) \\
\end{array}$ & $\begin{array}{c}0.337 \\
(0.470) \\
\end{array}$ & $\begin{array}{c}0.008 \\
(0.012) \\
\end{array}$ & $\begin{array}{c}-0.403 \\
(-0.415) \\
\end{array}$ \\
\hline Would you rather stay at home than do something you are not familiar with? & $\begin{array}{c}-0.199 \\
(-0.271) \\
\end{array}$ & $\begin{array}{c}-0.339 \\
(-0.486) \\
\end{array}$ & $\begin{array}{c}-0.137 \\
(-0.198) \\
\end{array}$ & $\begin{array}{c}-0.745 \\
(-0.844) \\
\end{array}$ \\
\hline Do you think your memory is worse than that of other peers? & $\begin{array}{c}0.665 \\
(1.012) \\
\end{array}$ & $\begin{array}{c}0.752 \\
(1.196) \\
\end{array}$ & $\begin{array}{c}0.755 \\
(1.214) \\
\end{array}$ & $\begin{array}{c}0.746 \\
(0.922) \\
\end{array}$ \\
\hline Do you feel useless? & $\begin{array}{c}-0.279 \\
(-0.393) \\
\end{array}$ & $\begin{array}{c}-0.723 \\
(-1.085) \\
\end{array}$ & $\begin{array}{c}-0.319 \\
(-0.489) \\
\end{array}$ & $\begin{array}{c}0.766 \\
(0.833) \\
\end{array}$ \\
\hline Do you feel energetic? & $\begin{array}{c}0.218 \\
(0.272) \\
\end{array}$ & $\begin{array}{c}-0.414 \\
(-0.547) \\
\end{array}$ & $\begin{array}{c}-0.630 \\
(-0.843) \\
\end{array}$ & $\begin{array}{c}-0.209 \\
(-0.222) \\
\end{array}$ \\
\hline Do you feel hopeless in your situation? & $\begin{array}{c}0.461 \\
(0.656) \\
\end{array}$ & $\begin{array}{c}0.466 \\
(0.695) \\
\end{array}$ & $\begin{array}{c}0.045 \\
(0.068) \\
\end{array}$ & $\begin{array}{c}0.595 \\
(0.659) \\
\end{array}$ \\
\hline $\begin{array}{l}\text { How often have you participated in physical exercise } \\
\text { (including dancing, walking, boxing, playing ball, etc.) in the past year? }\end{array}$ & $\begin{array}{c}0.060 \\
(0.264) \\
\end{array}$ & $\begin{array}{c}-0.047 \\
(-0.225) \\
\end{array}$ & $\begin{array}{c}0.010 \\
(0.050)\end{array}$ & $\begin{array}{c}-0.168 \\
(-0.619) \\
\end{array}$ \\
\hline How much time do you spend exercising each time in the past year? & $\begin{array}{l}1.433^{* *} \\
(2.861) \\
\end{array}$ & $\begin{array}{l}1.234^{* *} \\
(2.578) \\
\end{array}$ & $\begin{array}{l}1.151^{*} \\
(2.436)\end{array}$ & $\begin{array}{l}1.404^{*} \\
(2.436) \\
\end{array}$ \\
\hline $\begin{array}{l}\text { Will you take the initiative to care about international and domestic current affairs and politics in the past year? } \\
\text { (through newspapers, television, radio, etc.) }\end{array}$ & $\begin{array}{l}-0.163 \\
(-0.736) \\
\end{array}$ & $\begin{array}{c}0.019 \\
(0.092) \\
\end{array}$ & $\begin{array}{c}0.127 \\
(0.626) \\
\end{array}$ & $\begin{array}{c}0.083 \\
(0.316) \\
\end{array}$ \\
\hline Do you learn new skills and interesting knowledge by self-study or by taking classes? & $\begin{array}{l}-0.232 \\
(-0.377)\end{array}$ & $\begin{array}{c}-0.428 \\
(-0.725) \\
\end{array}$ & $\begin{array}{c}-0.761 \\
(-1.305) \\
\end{array}$ & $\begin{array}{c}0.676 \\
(0.829) \\
\end{array}$ \\
\hline Do you continue to work for public agency? & $\begin{array}{c}0.387 \\
(0.547)\end{array}$ & $\begin{array}{c}0.536 \\
(0.791)\end{array}$ & $\begin{array}{c}0.829 \\
(1.242)\end{array}$ & $\begin{array}{c}0.695 \\
(0.871)\end{array}$ \\
\hline Can your income support your basic living needs (clothing and food)? & $\begin{array}{c}-0.417 \\
(-0.969) \\
\end{array}$ & $\begin{array}{c}0.071 \\
(0.170) \\
\end{array}$ & $\begin{array}{c}0.329 \\
(0.801) \\
\end{array}$ & $\begin{array}{c}0.532 \\
(0.993) \\
\end{array}$ \\
\hline Have you saved or prepared for your pension? & $\begin{array}{c}-0.795 \\
(-1.933) \\
\end{array}$ & $\begin{array}{l}-0.920^{*} \\
(-2.379) \\
\end{array}$ & $\begin{array}{c}-0.367 \\
(-0.986) \\
\end{array}$ & $\begin{array}{c}0.344 \\
(0.735) \\
\end{array}$ \\
\hline
\end{tabular}


Research on the Resilient Regeneration

and Planning of Aging Community

in the Post COVID-19 Era

\begin{tabular}{|c|c|c|c|c|}
\hline Influence factors & Dissatisfied & Commonly & Satisfied & $\begin{array}{c}\text { Very } \\
\text { satisfied }\end{array}$ \\
\hline How secure are you to your surroundings when you go out alone? & $\begin{array}{c}1.228^{* *} \\
(2.848)\end{array}$ & $\begin{array}{l}1.341^{* *} \\
(3.214)\end{array}$ & $\begin{array}{c}1.277^{* *} \\
(3.111)\end{array}$ & $\begin{array}{c}2.519 * * \\
(4.454)\end{array}$ \\
\hline Are you free to provide financial support for your family? & $\begin{array}{l}0.739^{*} \\
(1.994) \\
\end{array}$ & $\begin{array}{l}0.729^{*} \\
(2.023)\end{array}$ & $\begin{array}{c}0.603 \\
(1.713)\end{array}$ & $\begin{array}{c}0.753 \\
(1.749) \\
\end{array}$ \\
\hline Intercept & $\begin{array}{c}-5.883 \\
(-1.737) \\
\end{array}$ & $\begin{array}{c}-3.909 \\
(-1.206)\end{array}$ & $\begin{array}{l}-8.195^{*} \\
(-2.509) \\
\end{array}$ & $\begin{array}{c}-20.691^{* *} \\
(-4.557) \\
\end{array}$ \\
\hline
\end{tabular}

Likelihood ratio test: $\chi^{2}(116)=256.540, p=0.000 \quad Y$ : Are you satisfied with the living experience in your community?

McFadden $R^{2}: 0.223$ Cox \& Snell $R^{2}: 0.455$ Nagelkerke $R^{2}: 0.487 * p<0.05 * * p<0.01$ the value in () is Z value

Table.3 Likelihood ratio test of multi classification logistic regression model

\begin{tabular}{cccccc}
\hline Model & -2Log Likelihood & Chi Square & df & BIC & \\
Intercept & 1148.079 & & & & \\
Final Model & 891.539 & 256.540 & 116 & 0.000 & 1131.539 \\
\hline
\end{tabular}




\section{Resilience regeneration and planning strategy for aging community}

Due to the serious impact of COVID-19, the daily activities of the elderly population have been restricted, and their physical and mental health has been affected. In order to solve this problem, based on the analysis of the current situation of the aging community, and from the perspective of improving the satisfaction of the elderly to the community environment, ensuring the safe travel of the elderly through resilience regeneration and planning of the community is an important premise and guarantee to improve the age friendly level of the aging community under the influence of the epidemic and enhance the resilience and sustainable development ability of the community.Therefore, based on the needs of residents, we put forward the resilient regeneration and planning methods for aging communities from two levels — spacial and social economy.

\subsection{Resilient regeneration and planning at the material space level}

Our investigation found that the physical space environment of the community has weak cultural space foundation, few daily cultural activities, low-end commercial formats, insufficient vitality of commercial space, serious problems of industrial convergence, lack of utilization of community green space, weak landscape interaction space, and old public infrastructure. The utilization rate of public space is not high, and the community is closed and lack of communication.(Fig.11)

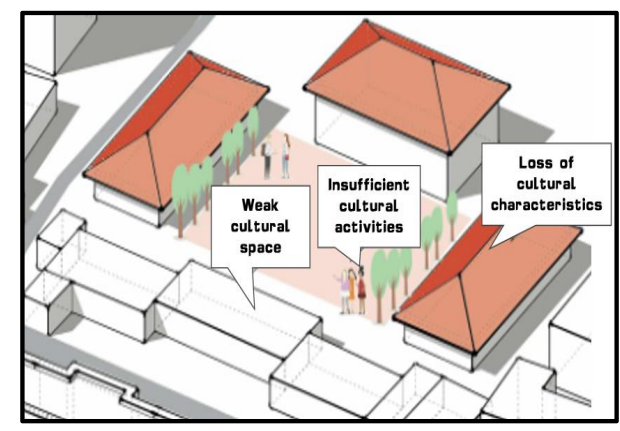

a.Cultural aphasia

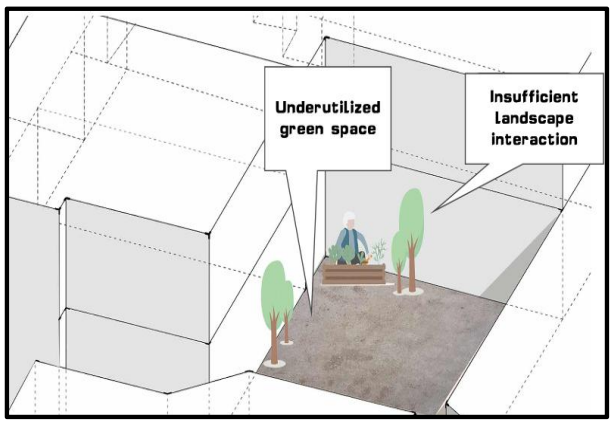

c.Ecological imbalance

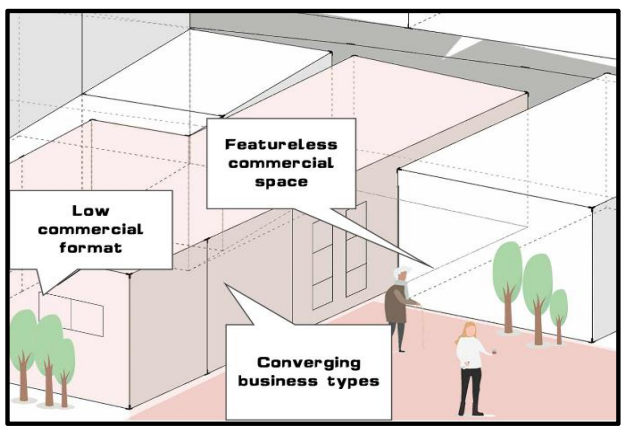

b. Industrial deactivation

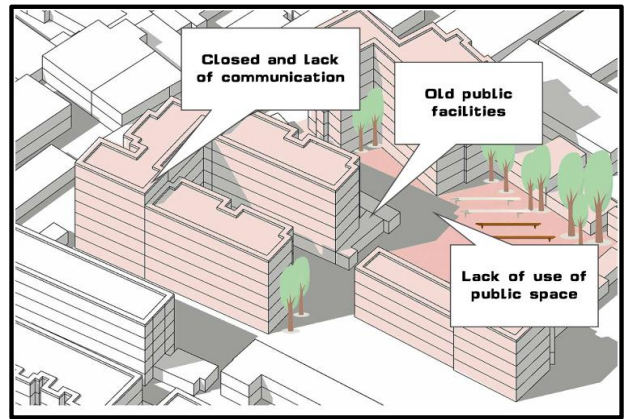

d. Space loss

Figure 11. Existing problems of spatial quality in aging communities

(Drawn by authors) 
Therefore, this study proposes the following community space resilience regeneration planning schemes:

(1) Reorganize the cultural space. Make full use of the cultural memory function of the historical and cultural heritage in the community, open up the spatial context of history and culture, and realize the continuation and reconstruction of culture, so that the community elderly in the post epidemic era can recover their cultural memory and enhance their sense of belonging and happiness.(Fig.12)

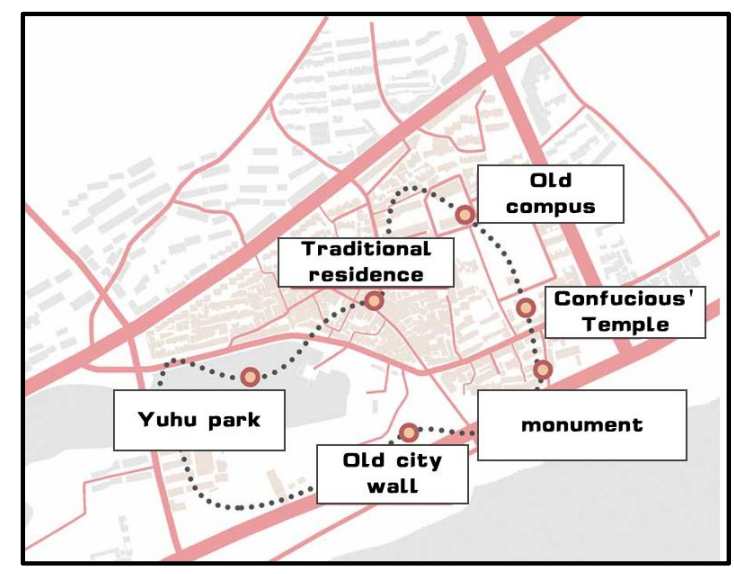

a.Cultural memory node

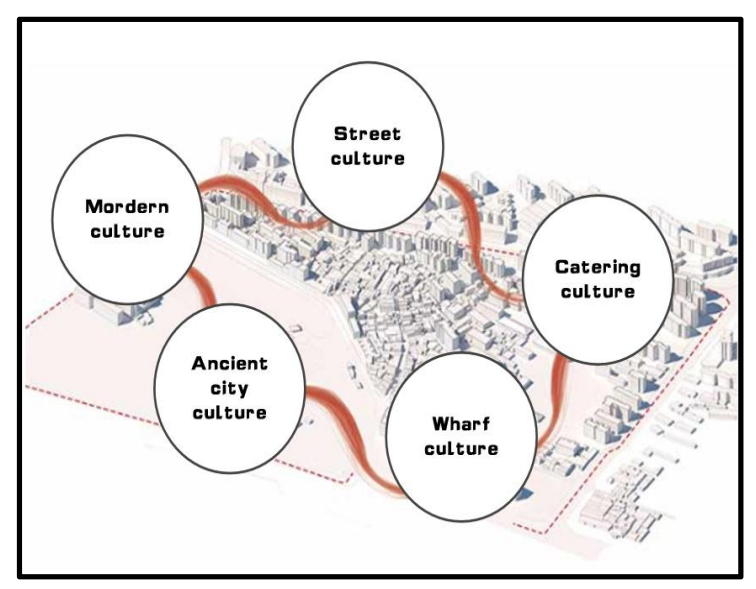

b.Interpretation of cultural connotation

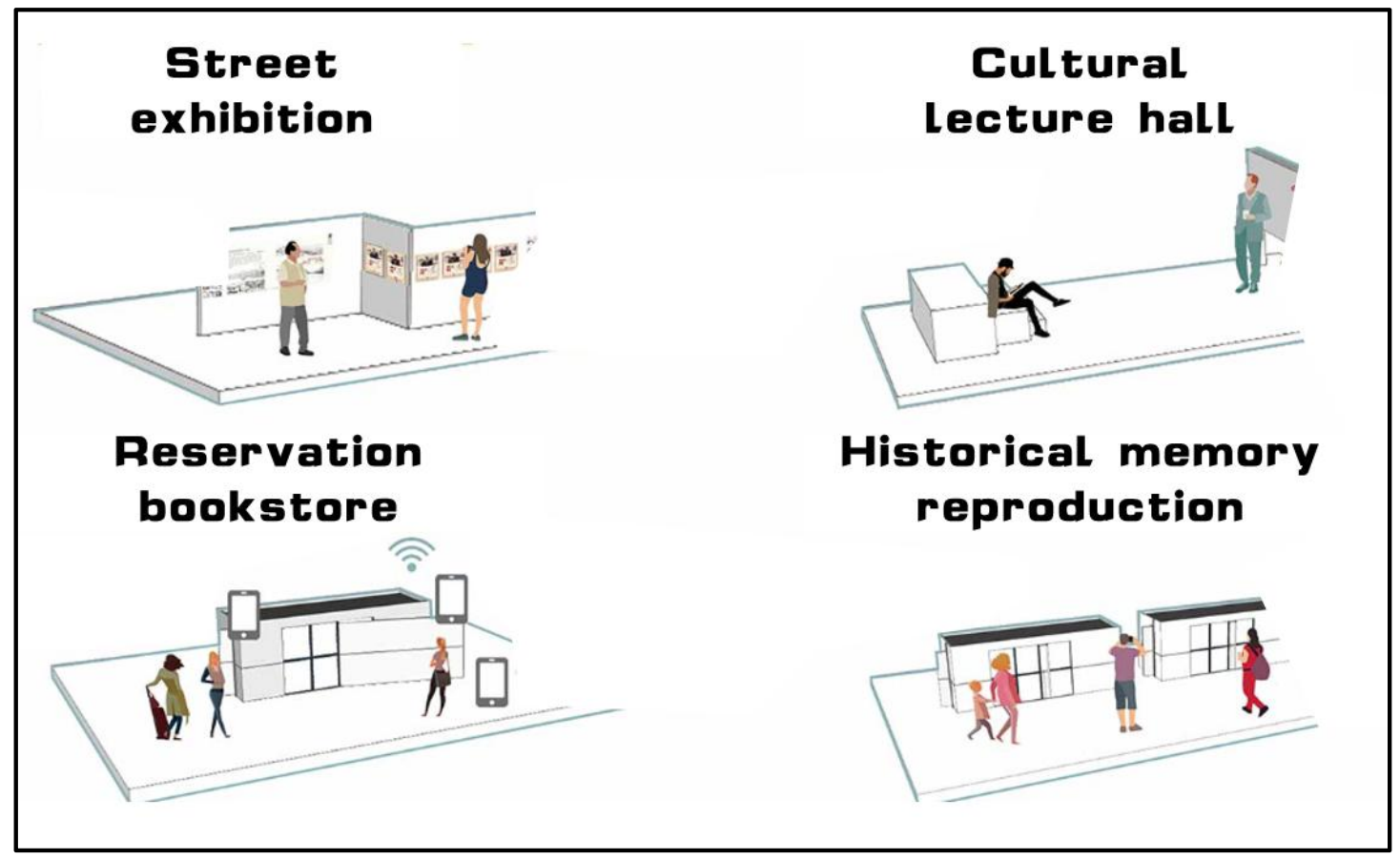

c.Street culture sharing

Figure 12. Cultural space reorganization

(Drawn by authors) 
(2) Update and transform the community space. Demolish damaged and dangerous buildings and temporary buildings, properly renew them on the basis of protecting traditional residential buildings, expand and enrich the functions of the original street space, introduce roof greening into old community buildings, expand the coverage of ecological environment, update the ventilation and lighting of old buildings, and create a new living space for the local elderly population, Improve the internal space use efficiency of the elderly, so that they can realize daily life, cultural life and outdoor activities without going out of the community.(Fig.13a)

(3) Improve the traffic system and shape the image of "slow community". Open up the road traffic network, orderly layer the road network, and realize the traffic micro-circulation within the community. In order to ensure the travel safety of the elderly, the community should realize the diversion of people and vehicles, and plan and configure parking. In order to avoid parking spaces occupying public space, the mixed parking mode of three-dimensional parking, underground parking or building front parking can be explored. Flexibly manage the road edge environment, reduce the lane width and broaden the spatial scale of sidewalks. Increase the diversity of community travel path selection, improve the radiation range of surrounding upper shops and public services, and enhance the vitality of the block. In addition, the road surface should be leveled and anti-skid treated. The road surface should be kept flat and paved to ensure that the road surface has no wide joints, meaningless bulges and other factors that are easy to cause the elderly to trip. Anti skid and waterproof pavement shall be adopted to ensure good road drainage and prevent all potential safety hazards.(Fig,13b,13c)

(4) Optimize public space and promote community communication. Fully tap the potential of space regeneration, organically integrate and update the closed residential space and semi open corner space, create a flexible community street space composed of buildings, living areas, activity space and walking space, and strengthen the relevance of space. According to the spacial needs of the elderly, an internal plastic activity space during the day and night should be created .(Fig.13d)

(5) Community ecological environment restoration. Make full use of the ecological environment advantages of Yuhu Park and Xiangjiang River near the community to create a landscape sight corridor. Through the ecological greening transformation of road corners and pedestrian space, as well as the landscape implantation of building enclosure and space, set up "pocket park" in the community. Build a special rainwater pipeline and build a roof water collection and circulation system to let the roof rainwater runoff and rainwater not absorbed by plants flow into the underground reservoir, which can be recycled after treatment; In the lower layer of green soil, porous materials are used to build a permeable layer, and rainwater storage spaces of different sizes and shapes are formed with the permeable interlayer.(Fig.14)

Through the above methods and means, the aging community will have more spatial vitality on the basis of the cultural atmosphere of the original historical block. In the post epidemic era, while keeping the neighborhood relatively closed (avoiding the inflow of infectious people), improving the social cycle within the neighborhood (making the elderly socialize nearby) can not only achieve the effect of epidemic prevention and control, but also achieve the social goal of the elderly, so as to achieve the ultimate goal of community space resilience renewal. 


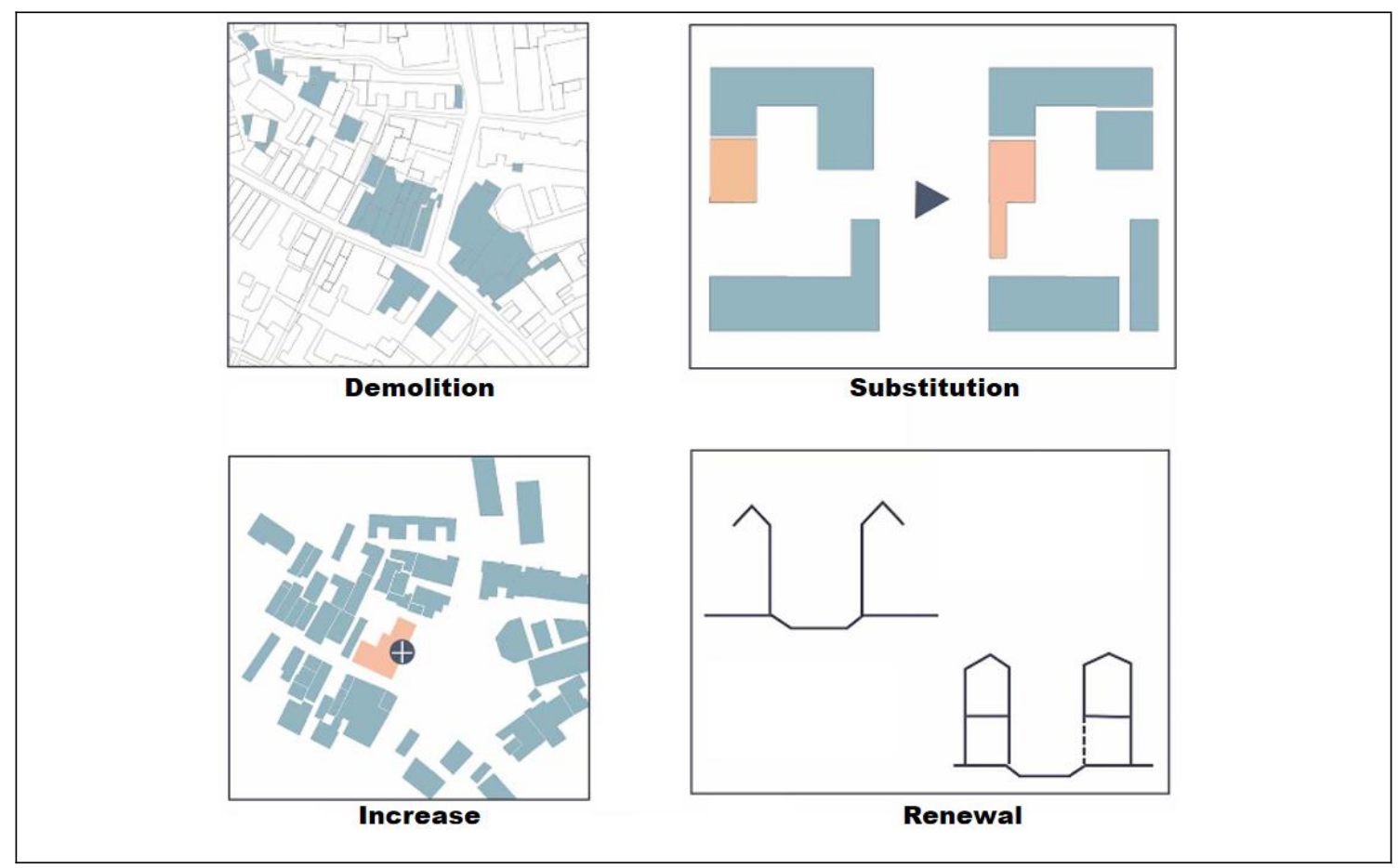

a. Renewal of old and dangerous buildings

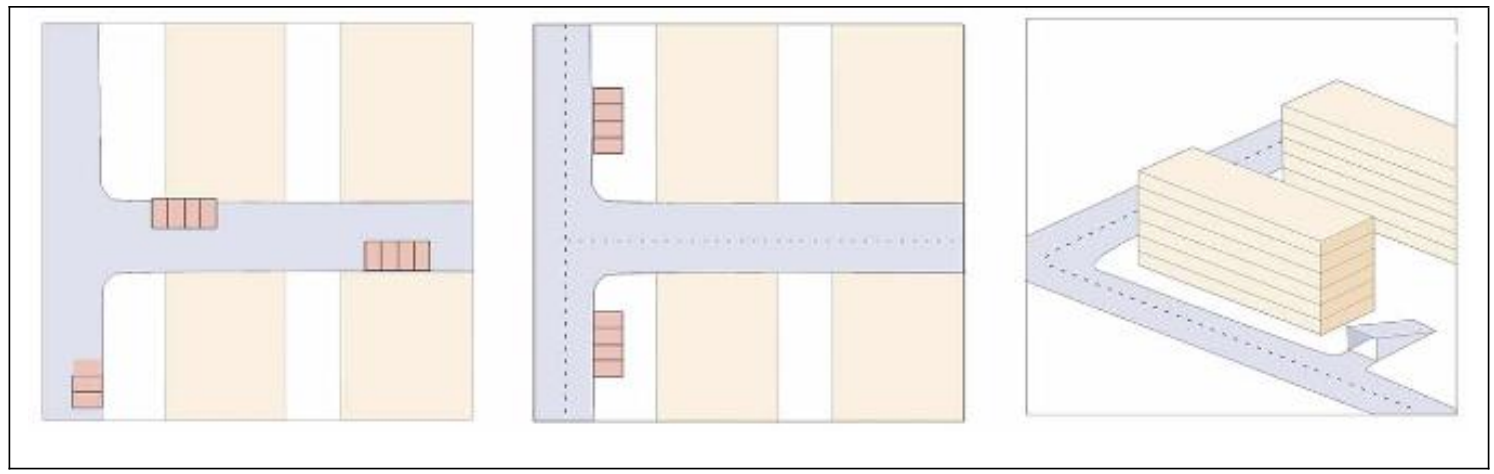

b. Regulate parking and dredge traffic flow

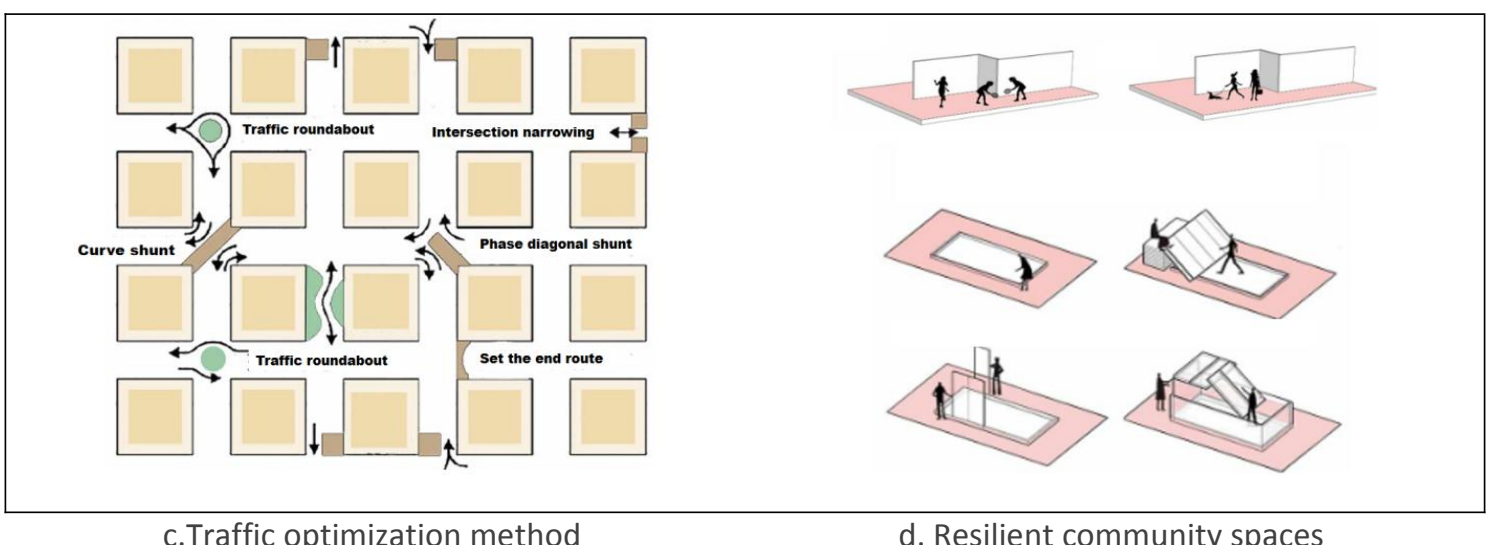

Figure 13. Resilience regeneration of aging community space

(Drawn by authors) 


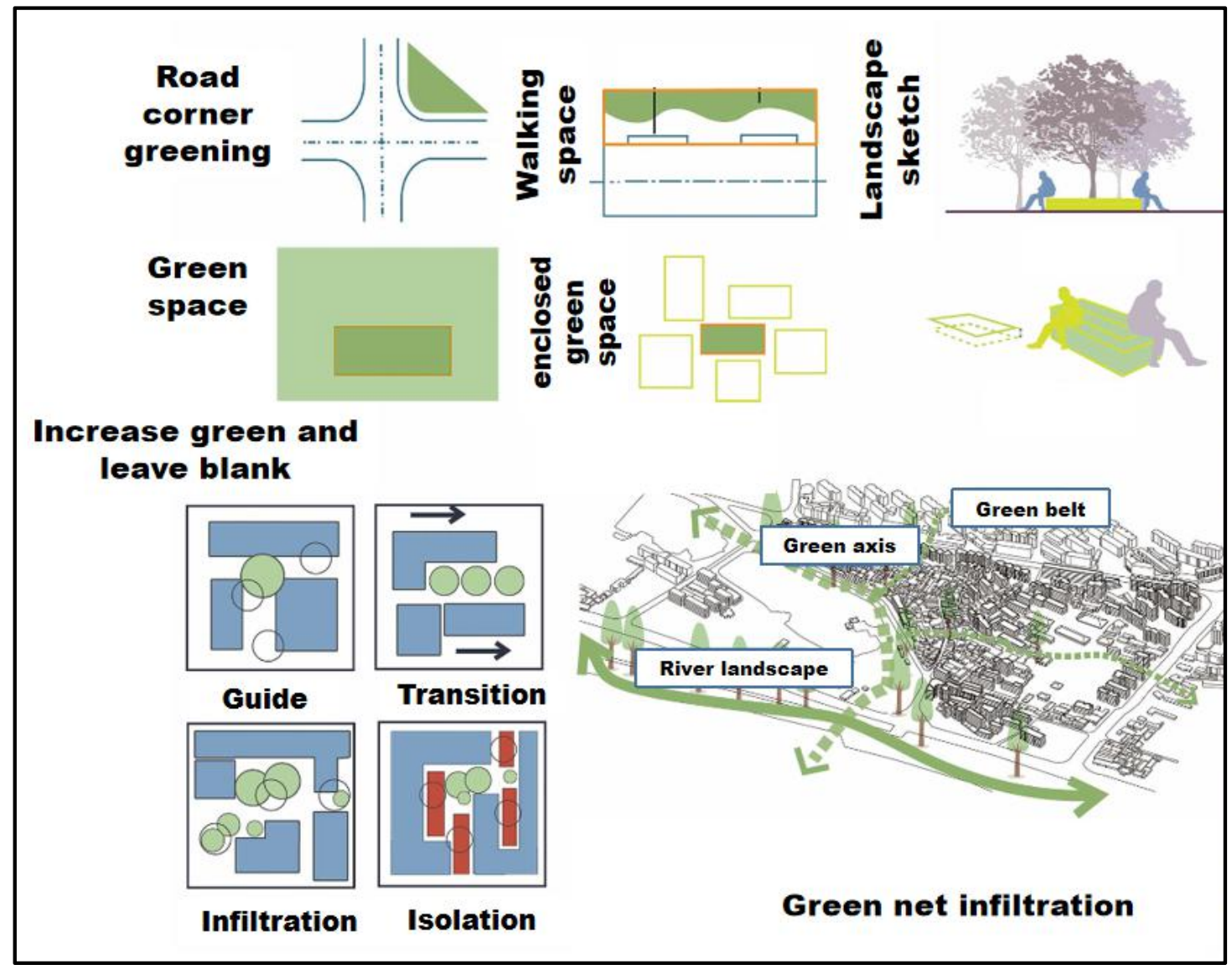

Figure 14. Ecological resilience restoration in aging community

(Drawn by authors)

\subsection{Resilience regeneration and planning at the socio-economic level}

At the socio-economic level, the tenacity regeneration of industrial space should be realized. Tap local characteristic culture and increase industrial vitality. Finding the potential ability of the community elderly to participate in reemployment is the goal of the elderly to participate in the development of community industrial form and realize active aging. Configure relevant industries according to different demand levels such as physiological needs, safety assurance, social activities and cultural experience, such as industries connected with culture and tourism, characteristic catering, characteristic home stay, characteristic cultural creation, photography and leisure, interactive exhibition, etc., so as to make the community's history and culture glow on the basis of retention. A virtuous circle of community industrial development will be constructed through four modes — residents' self reform, government transformation, semi market-oriented and market-oriented operation. Through this method and means, we can increase the income of local residents and solve the economic difficulties of the elderly. After the outbreak of the epidemic, there have been short fluctuations in domestic and foreign markets. How to ensure industrial prosperity is particularly important. Especially for the elderly, when the economic income is small, how to increase their income to achieve wealth freedom is also the goal that the resilient 
regeneration and planning of the aging community should achieve at a socio-economic level. At the same time, the community should irregularly hold fellowship activities and skill training according to the interests and hobbies of the elderly, so that the elderly can not only have a sense of security, but also have fun and even do something for the elderly.

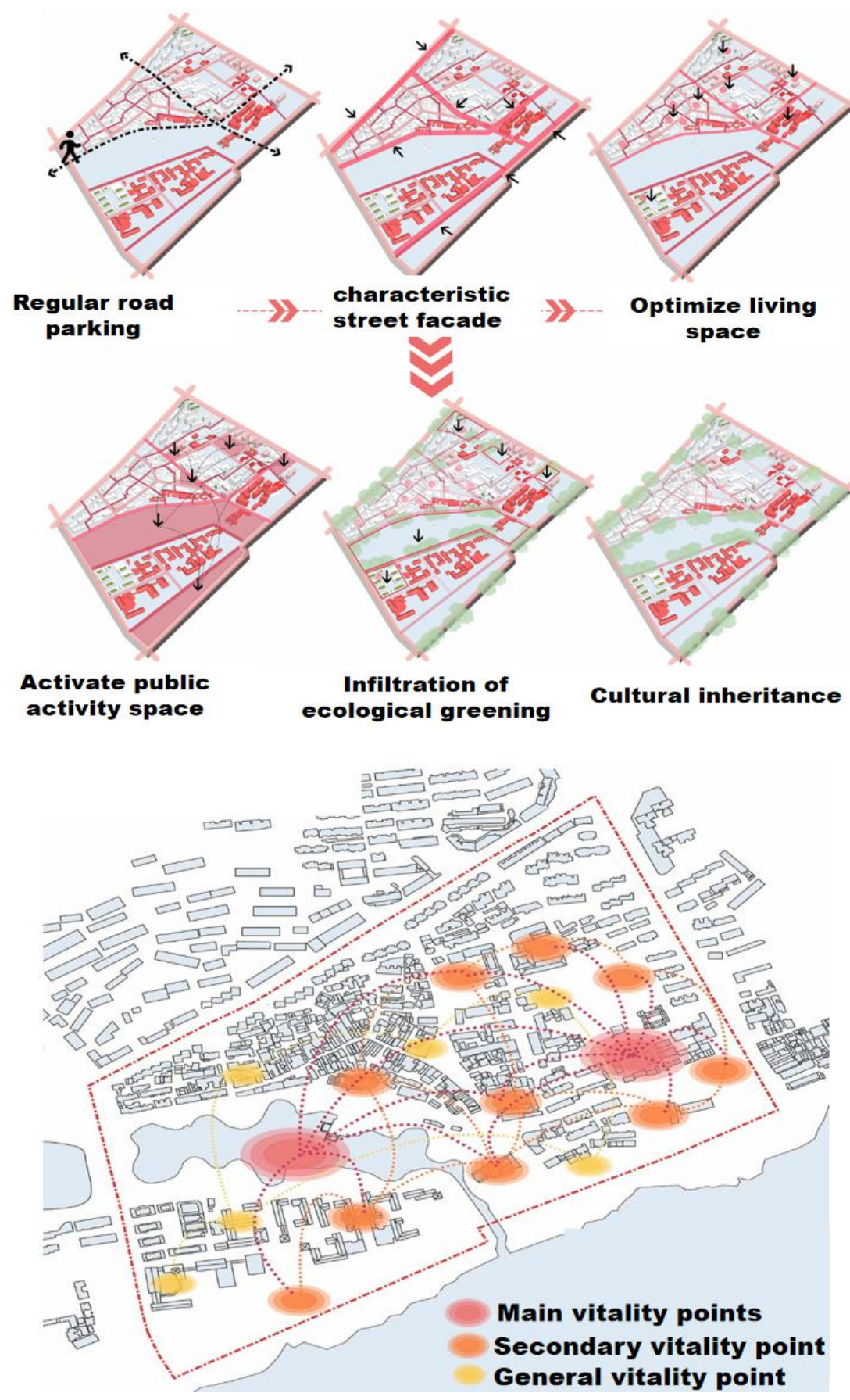

Figure 15. Space vitality map of resilience regeneration planning of aging community

(Drawn by authors) 


\section{Conclusions}

In the post COVID-19 era, the satisfaction of the elderly for community environment is significantly affected by social activities. The long-distance social activities of the elderly have a great test on their physical strength and are not conducive to their physical and mental health. Therefore, this paper proposes to organically regenerate the internal space of the elderly community under the concept of resilient city, and improve the quality of community space by means of cultural space organization, community facility renewal, transportation system improvement, public activity space optimization, material level resilient regeneration of ecological space restoration, and socio-economic level resilient regeneration of industrial space optimization. On the premise of ensuring public health safety, it is found that the above methods will ensure the social vitality of the elderly in the community, improve their satisfaction with the space environment, and promote the development of physical and mental health, so as to realize the resilience regeneration of the elderly community in the post COVID-19 era.

\section{Acknowledgement}

This work was supported by Ministry of Education Humanities and Social Sciences Fund(18YJCZH008), Hunan Natural Science Fund (2019JJ50171) ,Hunan Philosophy and Social Science Fund (17YBA165) and Hunan Education Department Excellent Youth Fund (19B195)

\section{References}

Burton C G. A Validation of Metrics for Community Resilience to Natural Hazards and Disasters Using the Recovery from Hurricane Katrina as a Case Study[J]. Annals of the Association of American Geographers, 2015, 105(1):67-86.

Bigger P, Webber S. Green structural adjustment in the World Bank's resilient city[J]. Annals of the American Association of Geographers, 2021, 111(1): 36-51.

Barnett J. Adapting to Climate Change in Pacific Island Countries: the Problem of Uncertainty[J]. World Development, 2001, 29(6): 977-993.

Bhuyan M R, Yuen B. Older Adults' Views of the Connections between Neighbourhood Built Environment and Health in Singapore[J]. Journal of Population Ageing, 2021: 1-21.

Choi Y, Kwon Y H, Kim J. The effect of the social networks of the elderly on housing choice in Korea[J]. Habitat International, 2018, 74: 1-8.

Coaffee J, Lee P. Urban resilience: Planning for risk, crisis and uncertainty[M]. Macmillan International Higher Education, 2016.

Coaffee J, Wood D M. Security is coming home: Rethinking scale and constructing resilience in the global urban response to terrorist risk[J]. International relations, 2006, 20(4): 503-517.

C. Folke, Resilience: The Emergence of a Perspective for Social-ecological Systems Analyses[J]. Global Environmental Change, 2006, 16(3): 253-267.

Clout H. Lawrence J. Vale, Thomas J. Campanella, eds. The Resilient City: How Modern Cities Recover from Disaster[J]. Journal of Historical Geography, 2007, 33(2): 458-459.

Desouza K C, Flanery T H. Designing, Planning, and Managing Resilient Cities: A Conceptual Framework[J]. Cities, 2013, 35(4): 89-99.

Evans J P. Resilience, Ecology and Adaptation in the Experimental City[J]. Transactions of the Institute of British Geographers, 2011, 36(2): 223-237.

Folke C. Resilience: The emergence of a perspective for social-ecological systems analyses[J]. Global environmental change, 2006, 16(3): 253-267.

Fleischhauer M. The role of spatial planning in strengthening urban resilience[M]//Resilience of Cities to 
Terrorist and other Threats. Springer, Dordrecht, 2008: 273-298.

Gunderson L H. South Florida: the reality of change and the prospects for sustainability: managing surprising ecosystems in Southern Florida[J]. Ecological economics, 2001, 37(3): 371-378.

Godschalk D R. Urban hazard mitigation: creating resilient cities[J]. Natural hazards review, 2003, 4(3): 136-143.

Holling C S. Resilience and stability of ecological systems[J]. Annual review of ecology and systematics, 1973, 4(1): 1-23.

Holling C S, Gunderson L H. Panarchy: understanding transformations in human and natural systems[M]. Washington, DC: Island Press, 2002.

Holling C S. Engineering Resilience Versus Ecological Resilience[J]. Engineering Within Ecological Constraints, 1996: 31-44.

Hatuka T, Rosen-Zvi I, Birnhack M, et al. The political premises of contemporary urban concepts: The global city, the sustainable city, the resilient city, the creative city, and the smart city[J]. Planning Theory \& Practice, 2018, 19(2): 160-179.

Jabareen Y. Planning the Resilient City: Concepts and Strategies for Coping with Climate Change and Environmental Risk[J]. Cities, 2013, 31: 220-229.

Jabareen Y. Planning the Resilient City: Concepts and Strategies for Coping with Climate Change and Environmental Risk[J]. Cities, 2013, 31: 220-229.

Liao $\mathrm{K} \mathrm{H}$. A theory on urban resilience to floods - a basis for alternative planning practices[J]. Ecology and society, 2012, 17(4).

Loo B P Y, Lam W W Y, Mahendran R, et al. How is the neighborhood environment related to the health of seniors living in Hong Kong, Singapore, and Tokyo? Some insights for promoting aging in place[J]. Annals of the American Association of Geographers, 2017, 107(4): 812-828.

Leung $\mathrm{M}$, Liang $\mathrm{Q}$. Developing structural facilities management-quality of life models for the elderly in the common areas of public and subsidized housings[J]. Habitat International, 2019, 94: 102067.

Levinger $\mathrm{P}$, Cerin E, Milner $\mathrm{C}$, et al. Older people and nature: the benefits of outdoors, parks and nature in light of COVID-19 and beyond-where to from here?[J]. International Journal of Environmental Health Research, 2021: 1-8.

Portegijs E, Keskinen K E, Tuomola E M, et al. Older adults' activity destinations before and during COVID19 restrictions: From a variety of activities to mostly physical exercise close to home[J]. Health \& Place, 2021, 68: 102533.

Parikh P, Diep L, Gupte J, et al. COVID-19 challenges and WASH in informal settlements: Integrated action supported by the sustainable development goals[J]. Cities (London, England), 2020, 107: 102871.

Pickett S T A, Cadenasso M L, Grove J M. Resilient Cities: Meaning, Models, and Metaphor for Integrating the Ecological, Socio-economic, and Planning Realms[J]. Landscape and Urban Planning, 2004, 69(4): 369-384.

Pendall R, Foster K A, Cowell M. Resilience and Regions: Building Understanding of the Metaphor[J]. Cambridge Journal of Regions, Economy and Society. 2010, 3(1): 71-84.

Satterthwaite D. The Political Underpinnings of Cities' Accumulated Resilience to Climate Change[J]. Environment and Urbanization, 2013,25(2): 381-391.

Suzuki Y, Maeda N, Hirado D, et al. Physical activity changes and its risk factors among communitydwelling Japanese older adults during the COVID-19 epidemic: associations with subjective well-being and health-related quality of life[J]. International journal of environmental research and public health, 2020, 17(18): 6591.

Sun Y, Fang Y, Yung E H K, et al. Investigating the links between environment and older people's place attachment in densely populated urban areas[J]. Landscape and Urban Planning, 2020, 203: 103897.

Subramanian D, Jana A. Assessing urban recreational open spaces for the elderly: A case of three Indian cities[J]. Urban Forestry \& Urban Greening, 2018, 35: 115-128.

Thomalla F, Downing T, Spanger-Siegfried E, et al. Reducing Hazard Vulnerability: Towards a Common Approach Between Disaster Risk Reduction and Climate Adaptation[J]. Disasters, 2006, 30(1): 39-48.

Wildavsky A B. Searching for safety[M]. Transaction Publishers, 1988. 
Yung E H K, Conejos S, Chan E H W. Social needs of the elderly and active aging in public open spaces in urban renewal[J]. Cities, 2016, 52: 114-122.

Yung E H K, Wang S, Chau C. Thermal perceptions of the elderly, use patterns and satisfaction with open space[J]. Landscape and urban planning, 2019, 185: 44-60.

Zhang F, Li D, Chan A P C. Diverse contributions of multiple mediators to the impact of perceived neighborhood environment on the overall quality of life of community-dwelling seniors: A crosssectional study in Nanjing, China[J]. Habitat International, 2020, 104: 102253. 